\title{
ПРИОРИТЕТЫ И НАПРАВЛЕНИЯ РАЗВИТИЯ СТРАТЕГИИ ТРАНСПОРТНОЙ ИНТЕГРАЦИИ В ЕАЭС
}

\section{PRIORITIES AND DIRECTIONS OF DEVELOPMENT OF THE TRANSPORT INTEGRATION STRATEGY IN THE EEU}

\section{Komov}

Summary. The purpose of the study is to identify the main priorities and directions of transport integration of the countries of the Eurasian economic Union, the development of transport networks and identify the basic problems that hinder the rapid integration of transport systems of the member countries into the single Eurasian system. The article presents an analysis of the state and identifies the main strategic development priorities that are important for overcoming the crisis in the transport industry.

Keywords: transport system; Eurasian space; transport policy; strategic directions.

\author{
Комов Михаил Сергеевич \\ К.э.н., дочент, Российский университет \\ транспорта, г. Москва \\ ecter@bk.ru
}

Аннотация. Целью исследования является выявление основных приоритетов и направлений транспортной интеграции стран Евразийского экономического союза, развития транспортных сетей и определения базовых проблем, препятствующих быстрой интеграции транспортных систем стран-членов в единую евразийскую систему. В статье представлен анализ состояния и обозначены основные стратегические приоритеты развития, которые имеют важное значение для преодоления кризиса в транспортной отрасли.

Ключевые слова: транспортная система; евразийское пространство; транспортная политика; стратегические направления.

ду [2]. В данной связи важным представляется выявление основных тенденций развития транспортных систем ЕАЭС и определения базовых проблем, препятствующих быстрой интеграции транспортных сетей стран-членов к единой евразийской сети, выделить основные направления развития евразийских транспортных сетей.

В течение последних десятилетий развитие транспортных сетей многих государств потерпел значительных потрясений, вызванных как внешними факторами, такими, как влияние кризисных явлений в экономике, так и внутренними - транспортные системы всех стран требуют капитальных изменений в соответствии с требованиями современного этапа развития мирового хозяйства. Транспорт - одна из самых важных отраслей хозяйства любого государства. Особое значение развитие транспортной отрасли приобретает в таком интеграционном объединении, как Евразийский экономический союз, главной целью которого является обеспечение свободного передвижения товаров, услуг и рабочей силы. Эффективное функционирование транспортной системы каждой из стран интеграционного объединения и их вовлечение в евразийскую и мировую транспортные сети будет способствовать решению важнейших задач современности и позволит увеличить объемы меж- 
дународных перевозок. Уровень развития транспортной сети - один из важнейших показателей экономической интеграции ЕАЭС в мировую экономику [6].

В начале XXI века каждое государство начала стремиться к тому, чтобы обеспечить постоянство экономического роста, улучшение уровня и качества жизни населения. Транспорт является одной из важнейших отраслей экономики, которые способствуют углублению интеграционных процессов. Под влиянием структурных изменений в экономике, прежде всего таких, как замена материало- и энергоемких отраслей наукоемкими, формируется мировая транспортная система, особенностью которой является фрагментарность развития. Перспективными направлениями развития транспортной отрасли стали уменьшения нагрузки на автомобильный транспорт, так как он имеет наибольшее негативное влияние на окружающую среду, совершенствование транспортных сетей с целью обеспечения безопасности перевозок, совершенствование транспортной инфраструктуры, внедрение инновационных транспортных систем и др. Особую актуальность развитие транспортной отрасли приобретает в интеграционных объединениях, главной целью большинства из которых является обеспечение свободного передвижения товаров, услуг и рабочей силы. Современная экономическая система является динамичной в связи с процессами глобализации, обусловливает необходимость постоянного исследования и корректировки (при необходимости) общих положений транспортной политики [1].

Развитие транспортных сетей является одной из главных задач транспортной политики ЕАЭС. Транспортные сети, которые эффективно функционируют, обеспечивают связи между странами, что является необходимым условием для устойчивого экономического развития и благосостояния граждан, а активизация интеграции национальных транспортных сетей стран ЕАЭС стимулирует не только региональное, но и международное сотрудничество [3].

Автомобильные транспортные сети ЕАЭС имеют наиболее высокие темпы развития из-за увеличения количества автомобилей. Наибольшие объемы перевозок выполняют предприятия транспортной отрасли таких стран, как Россия, Казахстан, Белоруссия, по территории которых проходят главные транспортные коридоры. Но следует отметить, что в течение последних пяти лет большинство стран ЕАЭС значительно сократили объемы грузовых перевозок автомобильным транспортом. Необходимо отметить, что рынок автомобильных перевозок на сегодняшнем этапе развития ЕАЭС является наиболее либерализированным. Но, несмотря на свободное перемещение автомобильного транспорта внутри ЕАЭС, в законодательстве каждой из стран-членов есть существенные различия по его использованию, например разрешенный уровень алкоголя в крови водителя или максимальная скорость движения. Наибольшей до сих пор не решенной проблемой ЕАЭС на рынке автомобильных перевозок является высокая загруженность дорог, загрязнение окружающей среды и высокий уровень смертности в дорожных авариях. Именно поэтому внедрение новых с точки зрения экологии технологий - одно из приоритетных направлений развития транспортных сетей ЕАЭС [5].

Железнодорожный транспорт стран ЕАЭС функционирует недостаточно эффективно. В течение последних лет доля этого вида транспорта в пассажирских и грузоперевозках сокращается. Однако, несмотря на сокращение удельного веса железнодорожного транспорта в общем объеме перевозок, за последние пять лет большинство стран-членов ЕАЭС активно наращивало темпы роста этого вида перевозок. На современном этапе развития железнодорожный транспорт не может на равных условиях конкурировать с другими видами транспорта: национальные железнодорожные пути и недостаточно интегрированы между собой. Но железнодорожный транспорт является наиболее безопасным, экологичным и относительно дешевым, поэтому ЕАЭС пытаются принимать наиболее актуальные решения по модернизации этого вида перевозок, и результатом транспортной политики в этом направлении является увеличение объемов перевозок именно у лидеров экономического и социального развития среди стран ЕАЭС.

Либерализация рынка авиаперевозок достаточно сложной процедурой, которая определяется темпами роста мировой экономики. Как наиболее быстрый и безопасный вид, авиационный транспорт развивается очень динамично соответствии с требованиями мировой экономики. Объемы авиаперевозок грузов являются наименьшими по сравнению с другими видами транспорта, однако удельный вес этого вида транспорта в пассажирообороте значительно выше.

Анализ объемов перевозок позволяет отметить, что использование того или иного средства перевозок существенно зависит от уровня экономического развития государства и степени ее интегрированности в мировое хозяйство, ведь наибольшие объемы перевозок демонстрируют те страны ЕАЭС, которые являются наиболее развитыми, к тому же транспортные сети этих стран охватываются всеми стратегически важными транспортными коридорами.

Реализация стратегических направлений интеграции транспортных систем является важной для повышения уровня конкурентоспособности как ЕАЭС в целом, так и каждой из стран-членов. Однако национальные 
интересы стран-членов ЕАЭС все еще противоречат единым намерениям: необходимы меры по дальнейшей либерализации рынка транспортных услуг, результатом которой должны стать усиление конкуренции, улучшения качества услуг и снижения цен. Кроме необходимости интеграции внутри ЕАЭС национальных и региональных транспортных сетей в одно целое, развитие транспортной отрасли приводит к возникновению других проблем, которые требуют немедленного решения. Так непропорциональное увеличение пропускных возможностей автомобильных дорог и аэропортов привело к появлению дорожных пробок и значительных затрат рабочего времени, что является наиболее весомым аргументом в дальнейшей реализации политики, направленной на развитие транспортных сетей ЕАЭС. На всех уровнях управления ЕАЭС становится понятным, что отсутствие единой транспортной политики, современной и эффективной транспортной системы приводит к сокращению темпов развития интеграционного объединения.

Основными составляющими данного интеграционного направления Стратегии развития транспортной отрасли ЕАЭС должны быть:

- повышение конкурентных позиций транспорта на международном рынке перевозок;

- сотрудничество различных видов транспорта и развитие комбинированных перевозок;

- унификация перевозочного процесса;

- формирование логистических цепей транспортных и грузовых потоков;

- совершенствование тарифной политики для повышения привлекательности транспорта как на национальном, так и на международном рынках транспортных перевозок;

- развитие транзитного потенциала.

Иными словами, транспорт является неотъемлемой частью развития интеграционных процессов. Он делает существенный вклад в интеграцию и рост внутреннего рынка, предоставляет евразийской экономике значительные преимущества. Многолетние усилия ЕАЭС по улучшению работы транспортного комплекса привели к возникновению нового представления о нем как единого целого. Евразийская транспортная политика определяет стандарты для сектора перевозок, таких, как улучшение условий работы, повышения безопасности и обеспечения прав пассажиров. Наиболее перспективными видами транспорта являются железнодорожный и водный транспорт, который призван разгрузить автодороги ЕАЭС и расширить транспортные сети. Совершенствование регулирования деятельности транспорта в ЕАЭС - это важнейшее направление экономических реформ, которые должны проводиться на современном этапе развития мировой экономики.
Для дальнейшего сотрудничества необходимо обеспечение условий для равного доступа на транспортный рынок операторов перевозок, создание на основе государственно-частного партнерства компаний-операторов перевозок, заинтересованных в увеличении объемов и эффективности перевозок и привлечения частных перевозчиков на железнодорожном транспорте. Не может не беспокоить этот факт, что на сегодняшний день уменьшается роль России как транзитера; недостаточность темпов и объемов развития транспортной инфраструктуры, технико-технологическое отставание которой существенно удорожает процесс доставки товара и приводит к переориентации транспортных потоков в обход территории России; неудовлетворительное состояние дорог, которые нуждаются в реконструкции или ремонте, средняя скорость движения на автодорогах ЕАЭС в 2-3 раза ниже, чем в западноевразийских странах, на отечественных дорогах становится экономически невыгодной эксплуатация современных автомобилей с улучшенными техническими и экологическими характеристиками. Также неудовлетворительное состояние железнодорожных путей, участки которых пришли в неудовлетворительное состояние и подлежат замене в силу возраста и длительную эксплуатацию; отсутствие надлежащего сервиса и внимания к насущным потребностям клиентов со стороны государственных транспортных монополий и государственных контролирующих органов и служб; несогласованность тарифной политики.

Таким образом, объективные интеграционные процессы обуславливают необходимость технологической, организационной и экономической совместимости национального транспорта с едиными транспортными структурами. Основные стратегические приоритеты должны разрабатываться на основе изучения следующих направлений: экономические и производственно-технологические особенности транспорта как фактора ускоренного развития и международной интеграции; основные направления евразийской транспортной политики и необходимость согласования стратегии развития транспорта с мировыми стандартами; состояние, приоритеты и основные факторы развития транспорта и транспортной инфраструктуры.

Стратегическими задачами являются конкретизация стратегических задач по видам транспорта и общим транспортным процессам. Анализ состояния и намеченные приоритеты для развития транспорта являются основой для дальнейших исследований и эффективного принятия управленческих решений на всех уровнях. Таким образом, может быть гарантировано ускоренное развитие транспорта, а также возможности для него соответствовать растущим потребностям транспортных услуг. 


\section{ЛИТЕРАТУРА}

1. Асаул М.А., Мохов А. Е., Шаталова Н. В. Перспективы строительства Евразийского канала // Транспорт Российской Федерации. Журнал о науке, практике, экономике. 2019. № 1 (80). С. 8-13.

2. Борисова В.В., Печенко Н. С. Интеграция и координация логистических потоков в Евразийском экономическом союзе // Вестник РГЭУ РИНХ. 2019. № 1 (65). C. 27-33.

3. Высоцкая В. Перспективы развития транзитного потенциала евразийского экономического союза // Экономика и бизнес: теория и практика. 2020 . № 5-1. C. 141-143.

4. Комов М. С. Сотрудничество в транспортной сфере как фактор развития региональной экономической интеграции в евразийском экономическом союзе (ЕАЭС) // Московский экономический журнал. 2019. № 13. С. 80-88.

5. Крутько А. А. Евразийские приоритеты России на современном этапе // Большая Евразия: Развитие, безопасность, сотрудничество. 2019. № 2-2. С. 178180.

6. Мешкова Т.А., Изотов В.С., Демидкина О. В., Кофнер Ю. К. ЕАЭС в меняющемся геополитическом контексте: приоритеты международного сотрудничества // Вестник РУДН. Серия: Политология. 2019. № 1. С. 7-33.

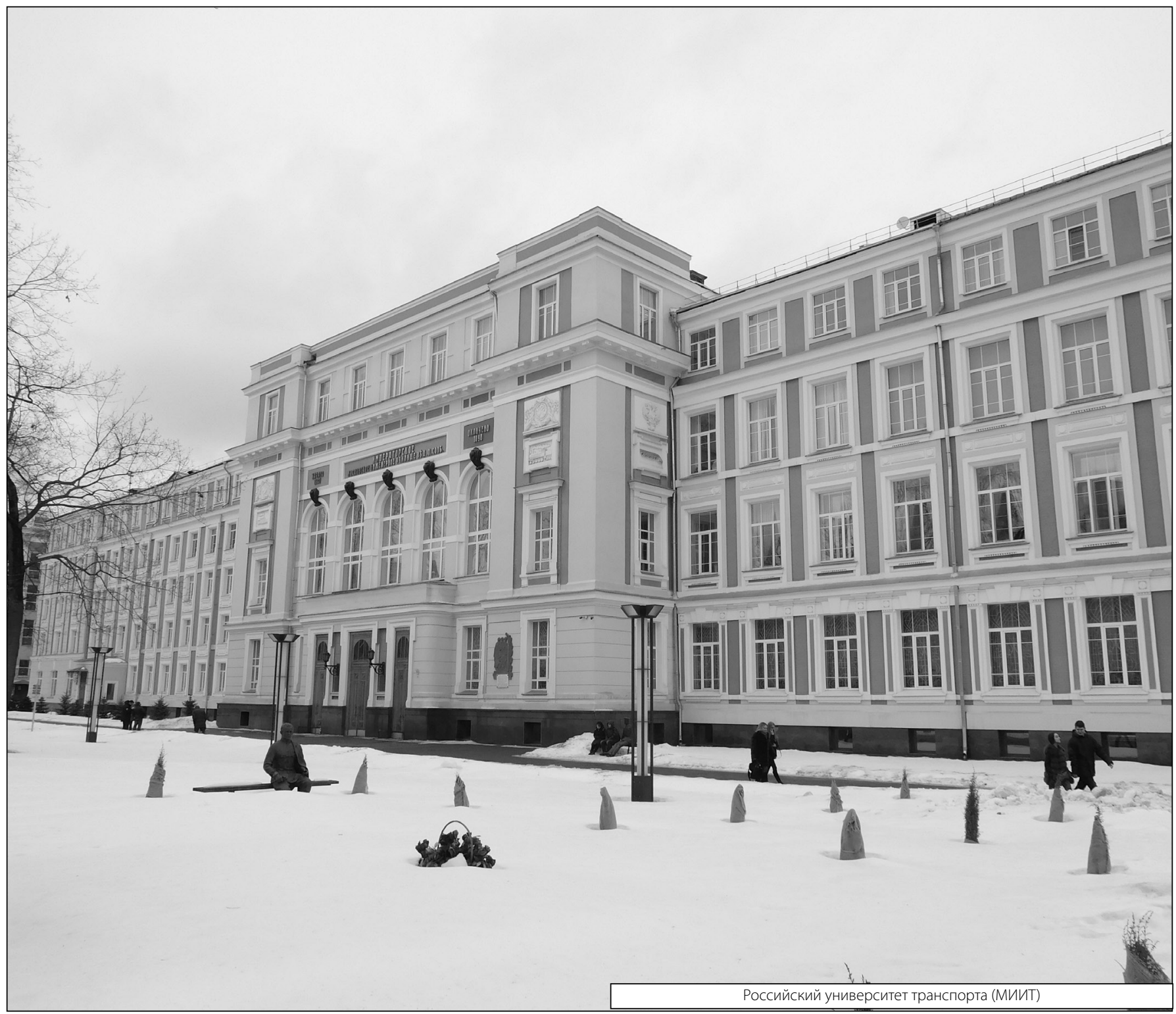

